\title{
Genetic Polymorphisms of Interleukin-1 Alpha and the Vitamin D Receptor in Mexican Mestizo Patients with Intervertebral Disc Degeneration
}

\author{
Salvador Cervin Serrano, ${ }^{1}$ Dalia González Villareal, ${ }^{2}$ \\ Maribel Aguilar-Medina, ${ }^{2}$ Jose Guillermo Romero-Navarro, ${ }^{2}$ \\ Jose Geovanni Romero Quintana, ${ }^{2}$ Eliakym Arámbula Meraz, ${ }^{2}$ \\ Ignacio Osuna Ramírez, ${ }^{2}$ Veronica Picos-Cárdenas, ${ }^{3}$ \\ Julio Granados, ${ }^{4}$ Iris Estrada-García, ${ }^{5}$ \\ Guzman Sánchez-Schmitz, ${ }^{6}$ and Rosalío Ramos-Payán ${ }^{2,7}$ \\ ${ }^{1}$ Division of Pain, ISSSTE Hospital, 80200 Culiacán, SIN, Mexico \\ ${ }^{2}$ Faculty of Biological and Chemical Sciences, Doctoral Programs in Biotechnology and Biomedical Sciences, \\ Autonomous University of Sinaloa, 80010 Culiacán, SIN, Mexico \\ ${ }^{3}$ Human Genetics Laboratory of the Research Unit, Faculty of Medicine, Autonomous University of Sinaloa, \\ 80019 Culiacán, SIN, Mexico \\ ${ }^{4}$ Division of Immunogenetics, National Institute of Medical Sciences and Nutrition, 14000 Mexico City, DF, Mexico \\ ${ }^{5}$ Department of Immunology, National School of Biological Science, National Polytechnic Institute, 11340 Mexico City, DF, Mexico \\ ${ }^{6}$ Division of Infectious Diseases, Boston Children's Hospital and Harvard Medical School, Harvard University, Boston, MA 02115, USA \\ ${ }^{7}$ Laboratory of Immunology, Faculty of Biological and Chemical Sciences, Autonomous University of Sinaloa, \\ Avenida de las Américas y Universitarios s/n, Ciudad Universitaria, 80010 Culiacán, SIN, Mexico
}

Correspondence should be addressed to Rosalío Ramos-Payán; ramospayan@yahoo.com.mx

Received 11 September 2014; Accepted 12 November 2014; Published 20 November 2014

Academic Editor: Mohamed Salem

Copyright (C) 2014 Salvador Cervin Serrano et al. This is an open access article distributed under the Creative Commons Attribution License, which permits unrestricted use, distribution, and reproduction in any medium, provided the original work is properly cited.

Intervertebral disc degeneration (IDD) is the most common diagnosis in patients with back pain, a leading cause of musculoskeletal disability worldwide. Several conditions, such as occupational activities, gender, age, and obesity, have been associated with IDD. However, the development of this disease has strong genetic determinants. In this study, we explore the possible association between rs1800587 (c.-949C>T) of interleukin-1 alpha (IL1A) and rs2228570 (c.2T>V) and rs731236 (c.1056T>C) of vitamin D receptor $(V D R)$ gene polymorphisms and the development of IDD in northwestern Mexican Mestizo population. Gene polymorphisms were analyzed by polymerase chain reaction followed by restriction fragment length polymorphism, in two groups matched by age and gender: patients with symptomatic lumbar IDD $(n=100)$ and subjects with normal lumbar-spine MRI-scans $(n=100)$. Distribution of the mutated alleles in patients and controls was $27.0 \%$ versus $28.0 \%(P=0.455)$ for T of rs1800587 (IL1A); $53.0 \%$ versus $58.0 \%(P=0.183)$ for $\mathrm{V}$ of rs $2228570(V D R)$; and $18.0 \%$ versus $21.0 \%(P=0.262)$ for $\mathrm{C}$ of rs731236 (VDR). Our results showed no association between the studied polymorphisms and IDD in this population. This is the first report on the contribution of gene polymorphisms on IDD in a Mexican population.

\section{Introduction}

Intervertebral disc degeneration (IDD) is one of the most common musculoskeletal disorders. IDD is often diagnosed in patients suffering back pain and is an important contributor to workforce-absence with staggering economic impact worldwide $[1,2]$.

Spinal degeneration includes both osteoarthritic changes of the facet joint and IDD. Pathophysiology of disc degeneration is not well understood and is thought to 
occur gradually with aging. Recently, a study in Finnish postmenopausal women showed that higher lumbar bone mineral density (BMD) and $Z$-score from T2-weighted magnetic resonance imaging (MRI) were associated with more severe lumbar disc degeneration at L1-L4 levels [3], and experimental animal models have found that osteoporosis could have a role in IDD progression [4].

Decreased production of extracellular matrix (ECM), increased production of degrading enzymes, and increased expression of inflammatory cytokines in the intervertebral disc are usually observed in IDD. These findings may lead to several alterations including reduced strength of the nucleus pulposus and annulus fibrosus, dehydration, height reduction, trabecular fissures, end-plate changes, Schmorl nodes, osteophyte formation, spinal stenosis, disc bulging, herniation, and discogenic pain $[5,6]$. However, IDD often occurs without associated symptoms as demonstrated by the high incidence of degenerative changes in the asymptomatic population [7-9].

Environmental, behavioral, and anthropometric factors such as gender, obesity, height, occupational activities, and smoking have been associated with a higher risk for developing IDD. In contrast to the relatively minor contribution of these risk factors [10-12], twin-pair studies have found a strong familial aggregation and heritability for IDD [13-16]. In fact, genetic factors account for up to $75 \%$ of individual susceptibility to IDD [12, 16-19].

Association studies of genes encoding for structural and functional components of intervertebral disc have highlighted the participation of polymorphisms in IDD $[18,20-$ 22], including collagens I [23], IX [24], and XI [25], aggrecan [26], cartilage intermediate layer protein (CILP) [27], ECM-degrading enzymes such as MMP-3 [28] and MMP9, thrombospondin-2 (THBS2) [29], inflammatory cytokines interleukin-1 alpha (IL-1 $\alpha$ ) [30], IL-18 [21], IL-6, and tumor necrosis factor alpha (TNF- $\alpha)[31]$, and vitamin $\mathrm{D}$ receptor (VDR) [32].

The hormonal form of vitamin $\mathrm{D}$ (calcitriol) plays a key role in mineralization of bone, absorption of calcium from the gut, control of calcium and phosphate homeostasis, and regulation of parathyroid hormone secretion and may affect intervertebral disc maintenance by altering the sulfation of glycosaminoglycans as well as other changes relating to the nucleus pulposus ECM. Upon activation by vitamin $\mathrm{D}, \mathrm{VDR}$ forms a heterodimer with the retinoid-X receptor and binds to hormone response elements on the genome, resulting in the expression of several genes involved in mineral metabolism and other metabolic and immune pathways. Therefore, it seems possible that alterations in the function of the VDR could participate in the pathogenesis of IDD or other diseases where vitamin D plays a role on bone and cartilage maintenance. In fact, several studies have demonstrated a strong association between polymorphisms of the VDR gene with osteoporosis [33], osteoarthritis, and even IDD $[32,34]$. Allelic variants of FokI (c.2T>V) of VDR code for structurally different receptors; the product of $\mathrm{V}$ allele (mutated) shows relatively increased function, compared with the T allele (larger product). This functional SNP is not in linkage disequilibrium with adjacent polymorphisms and therefore could be considered independent and directly associated with pathological findings [35].

IL- $1 \alpha$ is a proinflammatory cytokine involved in the regulation of immune responses, inflammatory processes, hematopoiesis, and induction of apoptosis in response to cell injury. IL- $1 \alpha$, produced mainly by activated macrophages, neutrophils, and epithelial and endothelial cells, is thought to be involved in the pathogenesis of disc degeneration by increasing the production of ECM degradation enzymes and by inhibiting ECM synthesis [36-38]. Some polymorphisms of the IL- $1 \alpha$ gene (IL1A) have been associated with disc degeneration $[30,39]$.

The contribution of genetic factors on IDD has been studied mainly in Finnish, Spanish, Chinese, and Japanese populations, but not in Mexico. Therefore, in this work, we selected polymorphisms rs1800587 (c.-949C>T) of IL1A and rs2228570 (c.2T >V) and $\operatorname{rs731236~(c.1056T~}>C$ ) of $V D R$ to evaluate their potential association with lumbar IDD in a Mestizo population from Sinaloa, a northwestern state from México.

\section{Materials and Methods}

2.1. Study Subjects. The population studied consisted of two groups matched by age, gender, and ethnicity: consecutive unrelated patients with symptomatic lumbar IDD $(n=100)$ and nonrelated control individuals without IDD $(n=100)$.

Patients were subjected to T2-weighted MRI of the lumbar spine (L1-L5) to assess disc degeneration by decreased signal intensity, height reduction, bulging, annular tears, herniation, and osteophytes. Patients were diagnosed at the Division of Pain, ISSSTE Hospital, over a period of four years and were classified according to Modic changes on MRI, and the American Society of Neuroradiology (ASNR) criteria $[5,40]$. Controls were subjects who attended other divisions of the same hospital, with normal lumbar-spine MRI-scans and lifetime history of no chronic low back pain, accidental back injuries, or spine pathology. For both groups, cases, and controls, the inclusion criteria for age were from 18 to 50 years, both male and female, weight range from 45 to $90 \mathrm{Kg}$ and natives of the northwestern state of Sinaloa, México (for two previous generations). Exclusion criteria were the presence or history of spondylopathologies, spinal tumors, infections, traumatisms, diabetes, systemic lupus erythematosus, rheumatoid arthritis, osteoporosis and other bone diseases, fibromyalgia, and collagen pathologies.

Age, gender, weight, height, and body mass index (BMI) were registered. In accordance with the World Health Organization's categories, subjects with $\mathrm{BMI} \geq 25 \mathrm{~kg} / \mathrm{m}^{2}$ were considered overweight and $\geq 27$ as class-I obese. The Ethical and Research Committee of the ISSSTE Hospital approved this study, and written informed consent, according to the Helsinki Declaration, was obtained from all subjects before their enrollment in the study.

2.2. Blood Samples. Peripheral blood was collected by a single venipuncture from subjects. All blood samples were drawn in EDTA containing tubes according to guidelines approved by 
TABLE 1: Conditions and products of PCR-RFLP.

\begin{tabular}{|c|c|c|c|c|c|c|}
\hline Gene & SNPs & Primers & $\begin{array}{l}\mathrm{Tm} \\
\left({ }^{\circ} \mathrm{C}\right)\end{array}$ & $\mathrm{RE}$ & bp & $\begin{array}{l}\text { Alleles } \\
\text { (bp) }\end{array}$ \\
\hline IL1A & rs1800587 & $\begin{array}{l}5^{\prime} \text {-GCATGCCATCACACCTAGTT-3' } \\
5^{\prime} \text {-TTACATATGAGCCTTCCATG-3' }\end{array}$ & 56 & $\mathrm{NcoI}$ & 193 & $\begin{array}{l}\text { C: } 174 \text { and } 19 \\
\text { T: } 193\end{array}$ \\
\hline \multirow{2}{*}{$V D R$} & rs2228570 & $\begin{array}{l}5^{\prime} \text {-AGCTGGCCCTGGCACTGCTCTGCTCT- } 3^{\prime} \\
5^{\prime} \text {-ATGGAAACACCTTGCTTCTTCTCCCTC- } 3^{\prime}\end{array}$ & 60 & FokI & 265 & $\begin{array}{l}\text { f: } 197 \text { and } 68 \\
\text { F: } 265\end{array}$ \\
\hline & rs731236 & $\begin{array}{l}5^{\prime} \text {-CAGAGCATGGACAGGGAGCAAG-3' } \\
5^{\prime} \text {-GCAACTCCTCATGGCTGAGGTCTCA-3' }\end{array}$ & 59 & $\operatorname{Taq}^{\alpha} \mathrm{I}$ & 746 & $\begin{array}{l}\text { T: } 495 \text { and } 251 \\
\text { t: } 294,251 \text {, and } 201\end{array}$ \\
\hline
\end{tabular}

Tm: annealing temperature; RE: restriction enzyme.

the Internal Review Committee of the ISSSTE and processed within 1 hour.

\subsection{DNA Amplification and Restriction Fragment Length Poly-} morphism. Genomic DNA was isolated from whole blood using the salt precipitation method [41]. Gene polymorphisms were analyzed by polymerase chain reaction followed by restriction fragment length polymorphism (PCR-RFLP). Reaction conditions, primers, and restriction fragments are summarized in Table 1.

A region of $193 \mathrm{bp}$ spanning the rs1800587 polymorphic site at the promoter region of IL1A gene in chromosome 2 q14 (formerly c.-899C $>$ T or c.-949C $>$ T) was amplified and digested with $\mathrm{NcoI}\left(2 \mathrm{U}\right.$ for $2 \mathrm{~h}$ at $37^{\circ} \mathrm{C}$ ) [31]. Allele C (wild) has one restriction site giving two fragments of 174 and $19 \mathrm{bp}$, while allele $\mathrm{T}$ has no recognition site.

PCR product of $265 \mathrm{bp}$ containing the single nucleotide polymorphism (SNP) rs2228570 at the translation initiation codon of exon 2 of VDR gene in chromosome 12q13.11 (formerly c.2T>C) was digested with FokI ( $1 \mathrm{U}$ for $2 \mathrm{~h}$ at $37^{\circ} \mathrm{C}$ ) [31]. Allele $\mathrm{T}$ (ancestral) has one restriction site giving two fragments of 197 and $68 \mathrm{bp}$, while allele V (A, C, or G) has no recognition site. In the same way, the $747 \mathrm{bp}$ amplicon spanning the synonymous polymorphism rs731236 in exon 9 of $V D R$ gene (formerly c.352T $>C$ or c.1056T $>C$ ) [32] was cleaved with $\mathrm{TaqI}\left(2 \mathrm{U}\right.$ for $2 \mathrm{~h}$ at $\left.37^{\circ} \mathrm{C}\right)$. Allele $\mathrm{T}$ (ancestral) showed two fragments of 496 and $251 \mathrm{bp}$, while allele C generated an additional restriction site giving three fragments of 294, 251, and $201 \mathrm{bp}$.

2.4. Statistical Analysis. Demographic and clinical variables of patients and controls were presented as mean \pm SD and frequencies. Power calculation showed that a significance level of $P \leq 0.05$, one-tailed directional, would yield a power of $80 \%$ with a sample size of 96 individuals per group [42]. Differences in allelic, genotype, and haplotype frequencies were evaluated using Fisher's exact test. SNPs associations were tested under dominant and recessive genetic models, and odds ratios (OR) with $95 \%$ confidence intervals $(\mathrm{CI})$ were used as the measure of association between specific alleles and genotypes with IDD and its clinical subtypes [43]. Significant $P$ values were corrected with the Bonferroni test for multiple comparisons [44]. Hardy-Weinberg's equilibrium was calculated by $\chi^{2}$ test for all genotype combinations of each SNP in patients and controls. PASW v18.0 (SPSS Inc., Chicago,
IL, USA) and Arlequin v3.5.1.2 (Swiss National Science Foundation) software packages were used for analysis.

\section{Results and Discussion}

IDD is a complex pathology, and genetic predisposition could impact the physiological maintenance of intervertebral discs or the control of inflammation and pain $[15,19,22,45]$, ultimately leading to the clinical manifestations of IDD. Genetic studies on IDD have been carried out mainly in population of European (Finnish and Spanish) or Asian (Chinese and Japanese) ancestry, but not in Mexican Mestizos, a major population in North America. Our work, carried out in a northwestern Mexican population, represents the first report of genetic polymorphisms and IDD in a population with mixed native Mexican-European ancestry, also known as Mestizos.

Patients with IDD and control subjects with a mean age of $39.22( \pm 6.88)$ versus $39.13( \pm 6.80)$ years $(P=0.918)$ were included in this study. In both groups, $89.0 \%$ of individuals were female and $11.0 \%$ were male. BMI data between patients and controls was $25.99( \pm 4.33)$ versus $26.23( \pm 3.72) \mathrm{kg} / \mathrm{m}^{2}$ $(P=0.673)$. Both groups fell into the overweight World Health Organization category for BMI. Covariates followed a normal distribution according to the Kolmogorov-Smirnov test, with no statistically significant differences between the groups. Disc herniation was evident in $80.0 \%$ of the patients and herniation with intervertebral osteochondrosis in $20.0 \%$. The percentages of cases based on Modic changes of spine MRI were type I (56.0\%), type II (34.0\%), and type III (10.0\%). Clinical symptomatology included $36.0 \%$ with sciatica, $22.0 \%$ with lumbago, and $42.0 \%$ with lumbosciatica.

Our study on the rs1800587 polymorphism of the IL1A showed no significant association with IDD (Table 2). The distribution of $\mathrm{T}$ allele in patients and controls was $27.0 \%$ versus $28.0 \%(P=0.455$; $\mathrm{OR}=0.95$; $95 \% \mathrm{CI}=0.61-$ 1.47). Genotype frequencies between the groups $(P=0.455)$ were $4.0 \%$ versus $10.0 \%$ for TT; $45.0 \%$ versus $35.0 \%$ for CT; and $51.0 \%$ versus $55.0 \%$ for CC, respectively. However, other reports have shown an association between the $\mathrm{T}$ allele and IDD. A report on the Finnish population showed that $\mathrm{T}$ allele carriers have a higher risk $(\mathrm{OR}=2.4)$ of developing disc bulges than those without it [38]. Another study found that $\mathrm{T}$ allele was associated (2.5-fold risk) with Modic changes $[46,47]$. An analysis of occupational and genetic factors 
TABLE 2: Allelic ( $a f$ ) and genotype $(g f$ ) frequencies of ILIA and VDR polymorphisms in controls subjects and patients with IDD.

\begin{tabular}{|c|c|c|c|c|}
\hline \multirow{2}{*}{$\begin{array}{l}\text { SNPs } \\
\text { rs1800587 (IL1A }\end{array}$} & \multicolumn{2}{|c|}{$\begin{array}{l}\text { Patients } \\
(n=100)\end{array}$} & \multicolumn{2}{|c|}{$\begin{array}{l}\text { Controls } \\
(n=100)\end{array}$} \\
\hline & & & & \\
\hline Alleles & $n$ & af & $n$ & af \\
\hline $\mathrm{T}$ & 53 & 0.27 & 55 & 0.28 \\
\hline $\mathrm{C}$ & 147 & 0.74 & 145 & 0.73 \\
\hline Genotypes & $n$ & gf & $n$ & gf \\
\hline $\mathrm{TT}$ & 4 & 0.04 & 10 & 0.10 \\
\hline $\mathrm{CT}$ & 45 & 0.45 & 35 & 0.35 \\
\hline $\mathrm{CC}$ & 51 & 0.51 & 55 & 0.55 \\
\hline \multicolumn{5}{|c|}{ rs2228570 (VDR) } \\
\hline Alleles & $n$ & af & $n$ & af \\
\hline V & 105 & 0.53 & 115 & 0.58 \\
\hline $\mathrm{T}$ & 95 & 0.48 & 85 & 0.43 \\
\hline Genotypes & $n$ & gf & $n$ & gf \\
\hline VV & 20 & 0.20 & 32 & 0.32 \\
\hline TV & 65 & 0.65 & 51 & 0.51 \\
\hline TT & 15 & 0.15 & 17 & 0.17 \\
\hline \multicolumn{5}{|c|}{ rs731236 (VDR) } \\
\hline Alleles & $n$ & af & $n$ & af \\
\hline $\mathrm{C}$ & 35 & 0.18 & 41 & 0.21 \\
\hline $\mathrm{T}$ & 165 & 0.83 & 159 & 0.80 \\
\hline Genotypes & $n$ & gf & $n$ & gf \\
\hline $\mathrm{CC}$ & 4 & 0.04 & 3 & 0.03 \\
\hline TC & 27 & 0.27 & 35 & 0.35 \\
\hline TT & 69 & 0.69 & 62 & 0.62 \\
\hline
\end{tabular}

demonstrated that $\mathrm{T}$ allele represented a significant risk factor for the disc degeneration phenotype [48]. A study of a Danish population also found an association of this polymorphism with disc degeneration [39]. In contrast, a case-control study of a population of Spain found no association between $\mathrm{T}$ allele and symptomatic lumbar disc herniation [49]. The reason for this inconsistent association between the T allele and IDD may be due to ethnic differences in the studied populations, or by different haplotypes in the promoter or enhancer regions. Mexican Mestizo populations have a high degree of genetic heterogeneity [50], carrying Amerindian and a few European and African HLA haplotypes [51]. Moreover, the population studied by us in Mexico has a particular genetic background, since half of the most common haplotypes found in this population have a proposed European origin, most likely from Spanish origin [52]. Not surprisingly, the frequency of the $\mathrm{T}$ allele in our population $(28.0 \%)$ was similar to the one observed in a Spanish population (35.5\%) [49] and alike our results was not associated with IDD.

Genotype frequencies observed between patients and controls $(P=0.161)$ for rs 2228570 polymorphism of $V D R$ were $20.0 \%$ versus $32.0 \%$ for VV; $65.0 \%$ versus $51.0 \%$ for TV; and $15.0 \%$ versus $17.0 \%$ for TT, respectively (Table 2 ).
Frequencies of $\mathrm{V}$ allele were $53.0 \%$ versus $58.0 \%(P=0.183$; $\mathrm{OR}=0.81 ; 95 \% \mathrm{CI}=0.55-1.21)$. In the case of rs731236 allele $\mathrm{C}$ of $V D R$ (Table 2), the distribution in patients and controls was $18.0 \%$ versus $21.0 \%(P=0.262$; $\mathrm{OR}=0.82$; $95 \% \mathrm{CI}=0.49-1.35)$. Genotype frequencies $(P=0.262)$ were $4.0 \%$ versus $3.0 \%$ for CC; $27.0 \%$ versus $35.0 \%$ for TC; and $69.0 \%$ versus $62.0 \%$ for TT, respectively. In accordance with our allelic frequencies, a recent study on the association between VDR polymorphisms and BMD in postmenopausal Mexican women, allelic frequencies of 53\% for C of FokI and $27 \%$ for $\mathrm{V}$ of TaqI were reported in the control group [53]. Other reports have shown an association between these VDR polymorphisms and IDD. The report in a Finnish population that demonstrated for the first time that VDR polymorphism was associated with IDD quantitatively assessed signal intensities of thoracic and lumbar discs, finding those to be $12.9 \%$ worse in men with the TaqI CC genotype and 9.3\% in the men with FokI VV genotype [32]. Reports on Japanese [54], Chinese [55], Turkish [56], English [57], and Australian [58] populations also found association between $V D R$ polymorphisms and IDD.

Therefore, for all the studied polymorphisms (Table 2) there were no significant differences in the distribution of alleles and genotypes between the groups $(P>0.05)$ under the genetic models tested. The study of haplotypes showed no differences in frequencies between the groups for any combination of rs2228570 and rs731236 SNPs of VDR. The stratified analysis of the data (patients by pathology, symptomatology, and Modic changes) also showed no significant differences (all $P \geq 0.05$ ). The genotypes in the groups were not significantly different from the expected distribution for a population in a Hardy-Weinberg equilibrium, with the exception of rs2228570 (VDR) in patients $(P=0.010)$.

Our work assessed for the first time the potential contribution of gene polymorphisms on IDD in a Mexican Mestizo population with homogeneous genetic background, since both patients and controls were ethnically and geographically matched. The results showed that no association exists between the studied polymorphisms and IDD in this population. Further analysis of other relevant polymorphisms and more Mestizo populations may contribute to finding the genetic determinants of this disease in our country.

\section{Conclusion}

In conclusion, this is the first report on the potential contribution of gene polymorphisms on IDD in a Mestizo population in Mexico. Our results showed that there is no association of the IL1A (rs1800587) and VDR (rs2228570 and rs731236) polymorphisms with IDD. The study of more Mestizo populations and more candidate genes may provide further insight into the etiology of the disease.

\section{Consent}

Written consent was obtained from patients for publication of this work. 


\section{Conflict of Interests}

The authors declare that there is no conflict of interests regarding the publication of this paper.

\section{Authors' Contribution}

Salvador Cervin Serrano diagnosed and treated the patients; Salvador Cervin Serrano, Dalia González Villareal, Maribel Aguilar-Medina, Jose Geovanni Romero Quintana, Veronica Picos-Cárdenas, and Jose Guillermo Romero-Navarro performed the research; Julio Granados, Eliakym Arámbula Meraz, and Ignacio Osuna Ramírez analyzed the data; Salvador Cervin Serrano and Rosalío Ramos-Payán designed the research; Iris Estrada-García, Guzman Sánchez-Schmitz, and Rosalío Ramos-Payán wrote the paper. All authors read and approved the final paper.

\section{Acknowledgment}

This work was supported by CONACYT (106152).

\section{References}

[1] USBJD/USBJI, "Spine: low back and neck pain," in The Burden of Musculoskeletal Diseases in the United States, vol. 1, pp. 21-56, American Academy of Orthopaedic Surgeons, 2011.

[2] D. Chou, D. Samartzis, C. Bellabarba et al., "Degenerative magnetic resonance imaging changes in patients with chronic low back pain: a systematic review," Spine, vol. 36, supplement, no. 21, pp. S43-S53, 2011.

[3] S. Salo, V. Leinonen, T. Rikkonen et al., "Association between bone mineral density and lumbar disc degeneration," Maturitas, 2014.

[4] L. Wang, W. Cui, J. P. Kalala, T. V. Hoof, and B. G. Liu, "To investigate the effect of osteoporosis and intervertebral disc degeneration on the endplate cartilage injury in rats," Asian Pacific Journal of Tropical Medicine, vol. 7, no. 10, pp. 796-800, 2014.

[5] M. T. Modic, P. M. Steinberg, J. S. Ross, T. J. Masaryk, and J. R. Carter, "Degenerative disk disease: assessment of changes in vertebral body marrow with MR imaging," Radiology, vol. 166, no. 1, part 1, pp. 193-199, 1988.

[6] S. Roberts, H. Evans, J. Trivedi, and J. Menage, "Histology and pathology of the human intervertebral disc," The Journal of Bone \& Joint Surgery Series A, vol. 88, supplement 2, pp. 10-14, 2006.

[7] R. Quiroz-Moreno, G. Lezama-Suárez, and C. Gómez-Jiménez, "Disc alterations of lumbar spine on magnetic resonance images in asymptomatic workers," Revista Médica del Instituto Mexicano del Seguro Social, vol. 46, no. 2, pp. 185-190, 2008.

[8] S. D. Boden, D. O. Davis, T. S. Dina, N. J. Patronas, and S. W. Wiesel, "Abnormal magnetic-resonance scans of the lumbar spine in asymptomatic subjects. A prospective investigation," Journal of Bone and Joint Surgery A, vol. 72, no. 3, pp. 403-408, 1990.

[9] K. M. C. Cheung, J. Karppinen, D. Chan et al., "Prevalence and pattern of lumbar magnetic resonance imaging changes in a population study of one thousand forty-three individuals," Spine, vol. 34, no. 9, pp. 934-940, 2009.
[10] M. B. Jørgensen, A. Holtermann, F. Gyntelberg, and P. Suadicani, "Physical fitness as a predictor of herniated lumbar disc disease-a 33-year follow-up in the Copenhagen male study," BMC Musculoskeletal Disorders, vol. 14, article 86, 2013.

[11] J. A. Buckwalter, "Aging and degeneration of the human intervertebral disc," Spine, vol. 20, no. 11, pp. 1307-1314, 1995.

[12] L. Ala-Kokko, "Genetic risk factors for lumbar disc disease," Annals of Medicine, vol. 34, no. 1, pp. 42-47, 2002.

[13] M. C. Battie, T. Videman, L. E. Gibbons, L. D. Fisher, H. Manninen, and K. Gill, "Determinants of lumbar disc degeneration: a study relating lifetime exposures and magnetic resonance imaging findings in identical twins," Spine, vol. 20, no. 24, pp. 2601-2612, 1995.

[14] M. C. Batite, D. R. Haynor, L. D. Fisher, S. K. Gill, L. E. Gibbons, and T. Videman, "Similarities in degenerative findings on magnetic resonance images of the lumbar spines of identical twins," Journal of Bone and Joint Surgery-Series A, vol. 77, no. 11, pp. 1662-1670, 1995.

[15] P. N. Sambrook, A. J. MacGregor, and T. D. Spector, "Genetic influences on cervical and lumbar disc degeneration: a magnetic resonance imaging study in twins," Arthritis \& Rheumatology, vol. 42, no. 2, pp. 366-372, 1999.

[16] M. C. Battié, T. Videman, J. Kaprio et al., "The Twin Spine Study: contributions to a changing view of disc degeneration," The Spine Journal, vol. 9, no. 1, pp. 47-59, 2009.

[17] C. Bijkerk, J. J. Houwing-Duistermaat, H. A. Valkenburg et al., "Heritabilities of radiologic osteoarthritis in peripheral joints and of disc degeneration of the spine," Arthritis \& Rheumatology, vol. 42, no. 8, pp. 1729-1735, 1999.

[18] C. K. Kepler, R. K. Ponnappan, C. A. Tannoury, M. V. Risbud, and D. G. Anderson, "The molecular basis of intervertebral disc degeneration," Spine Journal, vol. 13, no. 3, pp. 318-330, 2013.

[19] S. Kalb, N. L. Martirosyan, M. Y. Kalani, G. G. Broc, and N. Theodore, "Genetics of the degenerated intervertebral disc," World Neurosurgery, vol. 77, no. 3-4, pp. 491-501, 2012.

[20] A. A. Patel, W. R. Spiker, M. Daubs, D. Brodke, and L. A. Cannon-Albright, "Evidence for an inherited predisposition to lumbar disc disease," Journal of Bone and Joint Surgery -Series A, vol. 93, no. 3, pp. 225-229, 2011.

[21] T. Videman, J. Saarela, J. Kaprio et al., "Associations of 25 structural, degradative, and inflammatory candidate genes with lumbar disc desiccation, bulging, and height narrowing," Arthritis \& Rheumatism, vol. 60, no. 2, pp. 470-481, 2009.

[22] J. E. Mayer, J. C. Iatridis, D. Chan, S. A. Qureshi, O. Gottesman, and A. C. Hecht, "Genetic polymorphisms associated with intervertebral disc degeneration," The Spine Journal, vol. 13, no. 3, pp. 299-317, 2013.

[23] S. M. F. Pluijm, H. W. Van Essen, N. Bravenboer et al., "Collagen type I $\alpha 1 \mathrm{Sp} 1$ polymorphism, osteoporosis, and intervertebral disc degeneration in older men and women," Annals of the Rheumatic Diseases, vol. 63, no. 1, pp. 71-77, 2004.

[24] S. Annunen, P. Paassilta, J. Lohiniva et al., "An allele of COL9A2 associated with intervertebral disc disease," Science, vol. 285, no. 5426, pp. 409-412, 1999.

[25] F. Mio, K. Chiba, Y. Hirose et al., "A functional polymorphism in COL11A1, which encodes the $\alpha 1$ chain of type XI collagen, is associated with susceptibility to lumbar disc herniation," American Journal of Human Genetics, vol. 81, no. 6, pp. 12711277, 2007. 
[26] Y. Kawaguchi, R. Osada, M. Kanamori et al., "Association between an aggrecan gene polymorphism and lumbar disc degeneration," Spine, vol. 24, no. 23, pp. 2456-2460, 1999.

[27] S. Seki, Y. Kawaguchi, K. Chiba et al., "A functional SNP in CILP, encoding cartilage intermediate layer protein, is associated with susceptibility to lumbar disc disease," Nature Genetics, vol. 37, no. 6, pp. 607-612, 2005.

[28] M. Takahashi, H. Haro, Y. Wakabayashi, T. Kawa-uchi, H. Komori, and K. Shinomiya, "The association of degeneration of the intervertebral disc with $5 \mathrm{a} / 6 \mathrm{a}$ polymorphism in the promoter of the human matrix metalloproteinase-3 gene," Journal of Bone and Joint Surgery, vol. 83, no. 4, pp. 491-495, 2001.

[29] Y. Hirose, K. Chiba, T. Karasugi et al., "A functional polymorphism in THBS2 that affects alternative splicing and MMP binding is associated with lumbar-disc herniation," The American Journal of Human Genetics, vol. 82, no. 5, pp. 1122-1129, 2008.

[30] S. Solovieva, J. Lohiniva, P. Leino-Arjas et al., "Intervertebral disc degeneration in relation to the COL9A 3 and the IL- $1 \beta$ gene polymorphisms," European Spine Journal, vol. 15, no. 5, pp. 613619, 2006.

[31] N. Noponen-Hietala, I. Virtanen, R. Karttunen et al., "Genetic variations in IL6 associate with intervertebral disc disease characterized by sciatica," Pain, vol. 114, no. 1-2, pp. 186-194, 2005.

[32] T. Videman, J. Leppävuori, J. Kaprio et al., "Intragenic polymorphisms of the vitamin $\mathrm{D}$ receptor gene associated with intervertebral disc degeneration," Spine, vol. 23, no. 23, pp. 2477-2485, 1998.

[33] R. J. Wood and J. C. Fleet, “The genetics of osteoporosis: vitamin D receptor polymorphisms," Annual Review of Nutrition, vol. 18, pp. 233-258, 1998.

[34] A. Colombini, S. Cauci, G. Lombardi et al., "Relationship between vitamin $\mathrm{D}$ receptor gene (VDR) polymorphisms, vitamin D status, osteoarthritis and intervertebral disc degeneration," The Journal of Steroid Biochemistry and Molecular Biology, vol. 138, pp. 24-40, 2013.

[35] A. G. Uitterlinden, Y. Fang, J. B. J. van Meurs, H. A. P. Pols, and J. P. T. M. van Leeuwen, "Genetics and biology of vitamin D receptor polymorphisms," Gene, vol. 338, no. 2, pp. 143-156, 2004.

[36] K. L. E. Phillips, N. Jordan-Mahy, M. J. H. Nicklin, and C. L. Le Maitre, "Interleukin-1 receptor antagonist deficient mice provide insights into pathogenesis of human intervertebral disc degeneration," Annals of the Rheumatic Diseases, vol. 72, no. 11, pp. 1860-1867, 2013.

[37] W. Ye, D. S. Huang, W. J. Chen et al., "Association of 86 bp variable number tandem repeat polymorphism of interleukin-1 receptor antagonist gene with lumbar disc disease," Nan Fang Yi Ke Da Xue Xue Bao, vol. 27, no. 10, pp. 1485-1488, 2007.

[38] S. Solovieva, S. Kouhia, P. Leino-Arjas et al., "Interleukin 1 polymorphisms and intervertebral disc degeneration," Epidemiology, vol. 15, no. 5, pp. 626-633, 2004.

[39] P. J. Eskola, P. Kjaer, I. M. Daavittila et al., "Genetic risk factors of disc degeneration among 12-14-year-old Danish children: a population study," International Journal of Molecular Epidemiology and Genetics, vol. 1, no. 2, pp. 158-165, 2010.

[40] M. T. Modic, T. J. Masaryk, J. S. Ross, and J. R. Carter, "Imaging of degenerative disk disease," Radiology, vol. 168, no. 1, pp. 177$186,1988$.
[41] S. Gustincich, G. Manfioletti, G. Del Sal, C. Schneider, and P. Carninci, "A fast method for high-quality genomic DNA extraction from whole human blood," BioTechniques, vol. 11, no. 3, pp. 298-302, 1991.

[42] M. Gail, R. Williams, D. P. Byar, and C. Brown, "How many controls?" Journal of Chronic Diseases, vol. 29, no. 11, pp. 723731, 1976.

[43] B. Woolf, "On estimating the relation between blood group and disease," Annals of Human Genetics, vol. 19, no. 4, pp. 251-253, 1955.

[44] T. V. Perneger, "What's wrong with Bonferroni adjustments," British Medical Journal, vol. 316, no. 7139, pp. 1236-1238, 1998.

[45] I. Tegeder and J. Lötsch, "Current evidence for a modulation of low back pain by human genetic variants," Journal of Cellular and Molecular Medicine, vol. 13, no. 8B, pp. 1605-1619, 2009.

[46] J. Karppinen, S. Solovieva, K. Luoma, R. Raininko, P. LeinoArjas, and H. Riihimäki, "Modic changes and interleukin 1 gene locus polymorphisms in occupational cohort of middle-aged men," European Spine Journal, vol. 18, no. 12, pp. 1963-1970, 2009.

[47] J. Karppinen, I. Daavittila, S. Solovieva et al., "Genetic factors are associated with modic changes in endplates of lumbar vertebral bodies," Spine, vol. 33, no. 11, pp. 1236-1241, 2008.

[48] I. M. Virtanen, J. Karppinen, S. Taimela et al., "Occupational and genetic risk factors associated with intervertebral disc disease," Spine, vol. 32, no. 10, pp. 1129-1134, 2007.

[49] J. Paz Aparicio, I. Fernández Bances, E. López-Anglada Fernández et al., “The $I L-1 \beta(+3953$ T/C) gene polymorphism associates to symptomatic lumbar disc herniation," European Spine Journal, vol. 20, no. 3, pp. 383-389, 2011.

[50] A. Moreno-Estrada, C. R. Gignoux, J. C. Fernandez-Lopez et al., "Human genetics. The genetics of Mexico recapitulates Native American substructure and affects biomedical traits," Science, vol. 344, no. 6189, pp. 1280-1285, 2014.

[51] R. Barquera, J. Zúñiga, R. Hernández-Díaz et al., “HLA class I and class II haplotypes in admixed families from several regions of Mexico," Molecular Immunology, vol. 45, no. 4, pp. 1171-1178, 2008.

[52] J. G. Romero-Quintana, L. O. Frías-Castro, E. Arámbula-Meraz et al., "Identification of novel mutation in cathepsin $\mathrm{C}$ gene causing Papillon-Lefèvre Syndrome in Mexican patients," $B M C$ Medical Genetics, vol. 14, no. 1, article 7, 2013.

[53] A. González-Mercado, J. Y. Sánchez-López, J. A. Regla-Nava et al., "Association analysis of vitamin D receptor gene polymorphisms and bone mineral density in postmenopausal MexicanMestizo women," Genetics and Molecular Research, vol. 12, no. 3, pp. 2755-2763, 2013.

[54] Y. Kawaguchi, M. Kanamori, H. Ishihara, K. Ohmori, H. Matsui, and T. Kimura, "The association of lumbar disc disease with vitamin-D receptor gene polymorphism," Journal of Bone and Joint Surgery-Series A, vol. 84, no. 11, pp. 2022-2028, 2002.

[55] K. M. C. Cheung, D. Chan, J. Karppinen et al., "Association of the Taq I allele in vitamin $\mathrm{D}$ receptor with degenerative disc disease and disc bulge in a Chinese population," Spine, vol. 31, no. 10, pp. 1143-1148, 2006.

[56] B. Eser, T. Cora, O. Eser et al., "Association of the polymorphisms of vitamin d receptor and aggrecan genes with degenerative disc disease," Genetic Testing and Molecular Biomarkers, vol. 14, no. 3, pp. 313-317, 2010. 
[57] A. M. Valdes, G. Hassett, D. J. Hart, and T. D. Spector, "Radiographic progression of lumbar spine disc degeneration is influenced by variation at inflammatory genes: a candidate SNP association study in the Chingford cohort," Spine, vol. 30, no. 21, pp. 2445-2451, 2005.

[58] G. Jones, C. White, P. Sambrook, and J. Eisman, "Allelic variation in the vitamin $\mathrm{D}$ receptor, lifestyle factors and lumbar spinal degenerative disease," Annals of the Rheumatic Diseases, vol. 57, no. 2, pp. 94-99, 1998. 

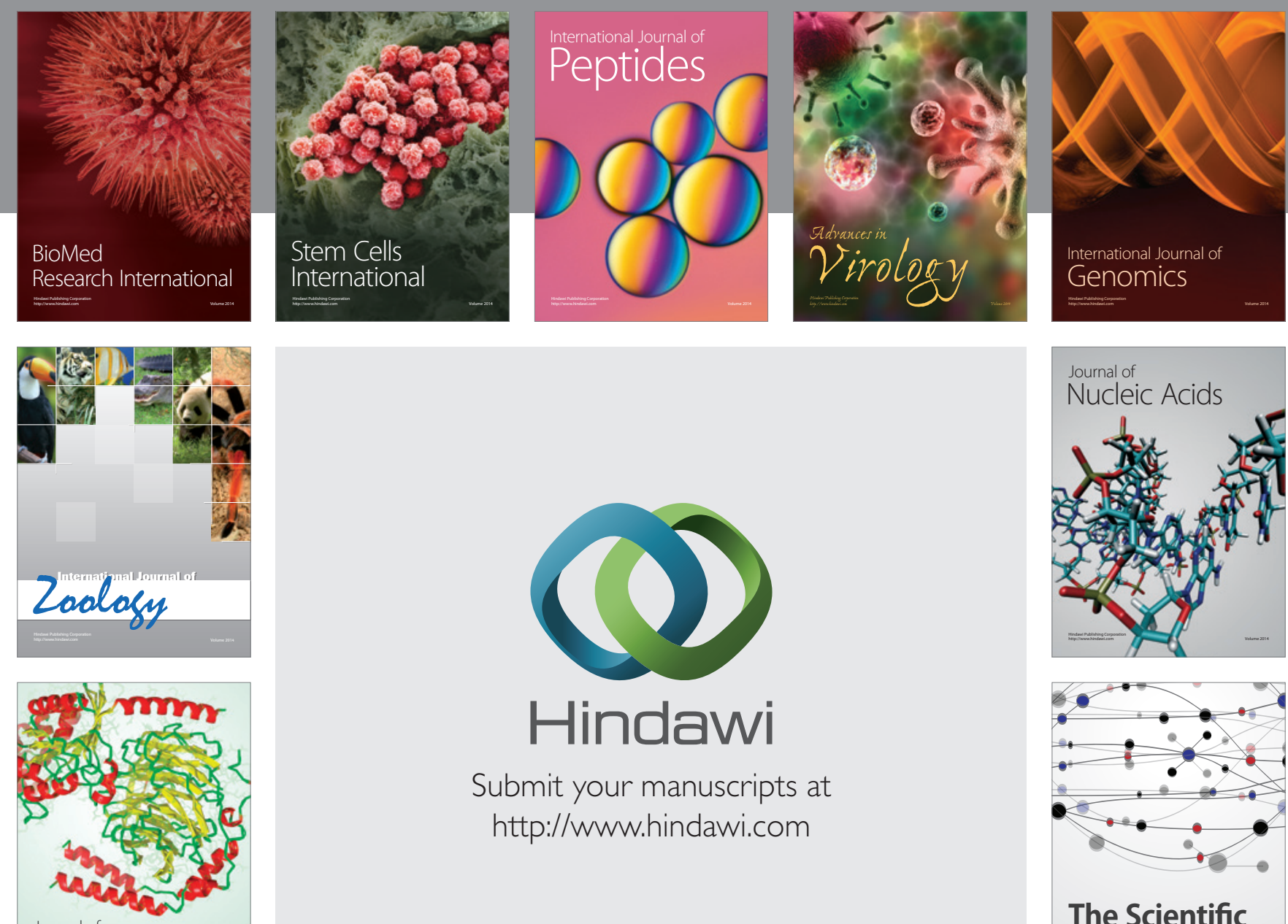

Submit your manuscripts at

http://www.hindawi.com

Journal of
Signal Transduction
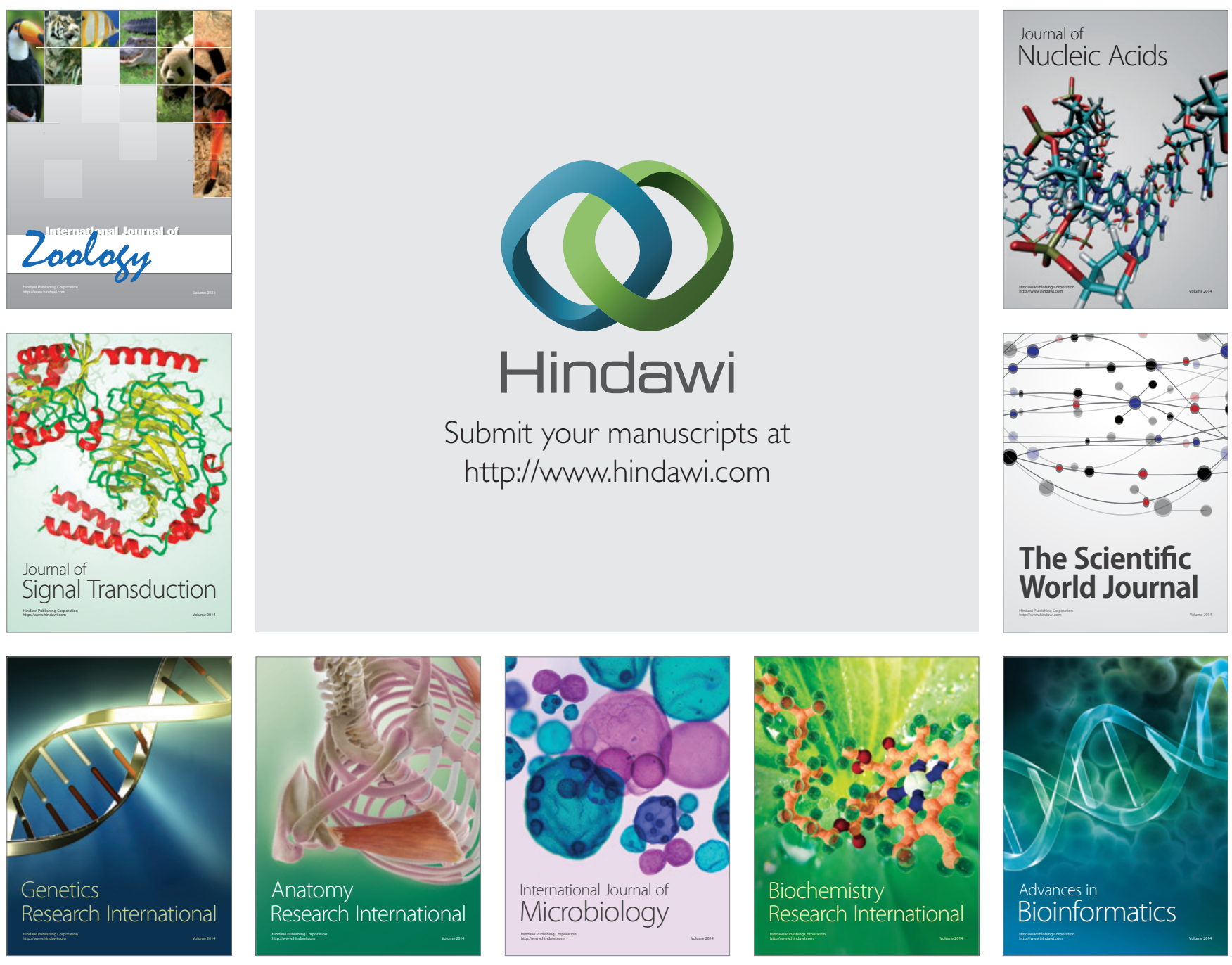

The Scientific World Journal
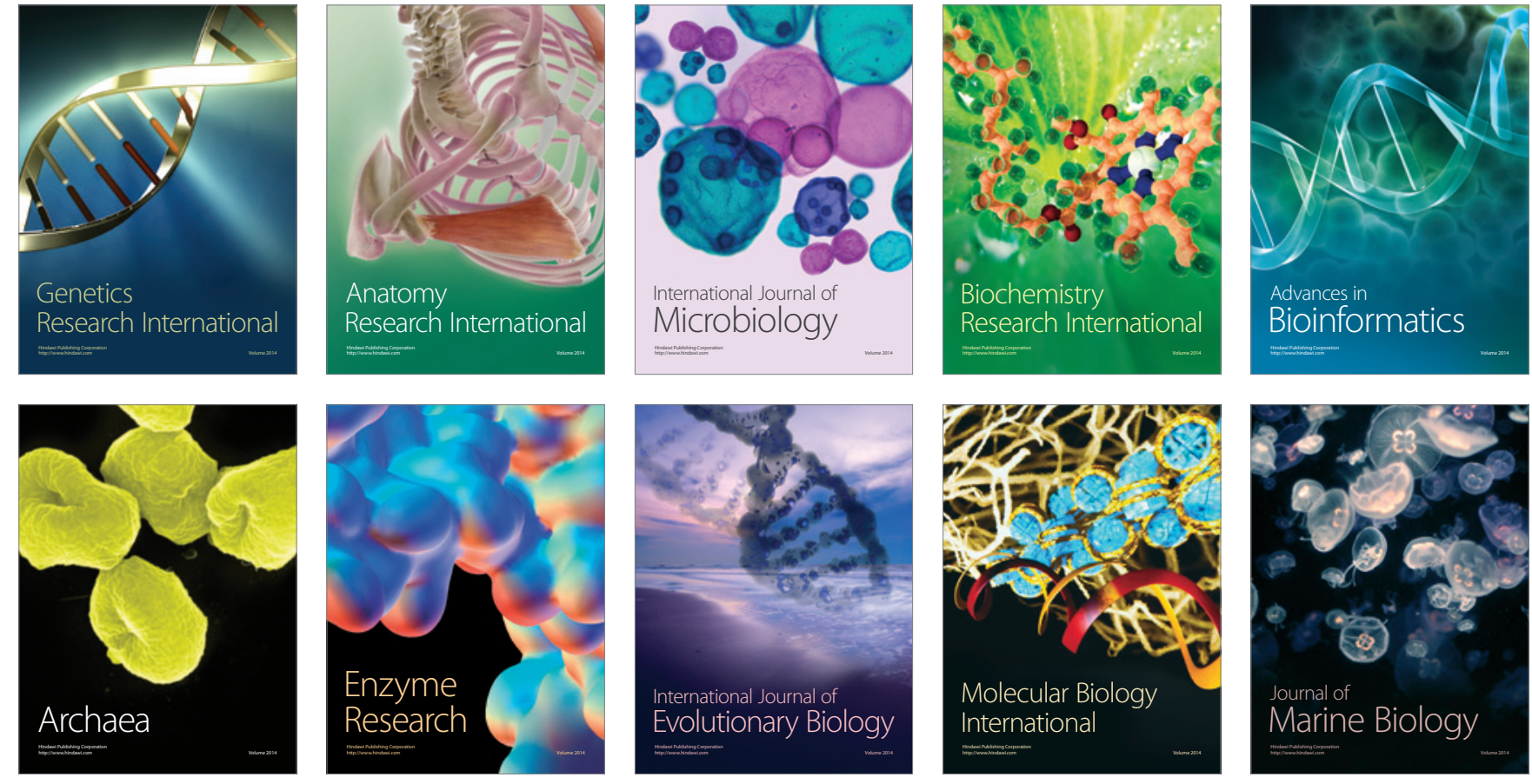